\title{
LANGUAGE LEARNING TECHNOLOGY REVIEW
}

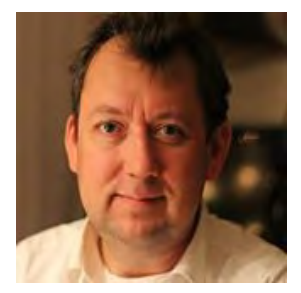

Jörg Waltje

Center for Excellence in Teaching and Learning, UAEU

- Non scholae, sed vitae discimus -

\section{FLIPPING THE CLASSROOM WITH EDUCANON}

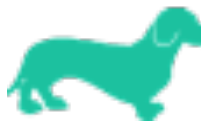

Over the last year or two "Flipping the Classroom" has become one of those buzz phrases that seem to follow an educator wherever he goes. Especially with the advent of Mobile Learning and the widespread use of tablet computers, flipping seems to be de rigeur, meaning: a new methodology that replaces traditional teaching and lecturing and thus promises better results for learning, student engagement, as well as retention of the learned materials. When we flip the classroom students are supposed to engage with the technologically sophisticated educational environment that can be created using computers or mobile devices outside of the classroom for previewing or -studying materials distributed to them electronically (via LMS, streaming video, etc.). The material can then be discussed, clarified, and analyzed in class; deeper, more thoughtful questions can be answered, no time will be wasted with lecturing or review. Students will master the materials at their own pace in the comfort of their home, or wherever else they want to, and

Vol. 44 (1) 2014 
they will come to class prepared for rigorous intellectual debate. The purpose of flipping the classroom is thus to shift from passive to active learning and to focus on higher order thinking skills such as analysis, synthesis and evaluation.

\section{What Is a Flipped Classroom?}

Cynthia Brame points out

In essence, "flipping the classroom" means that students gain first exposure to new material outside of class, usually via reading or lecture videos, and then use class time to do the harder work of assimilating that knowledge, perhaps through problem-solving, discussion, or debates. ${ }^{\text {i }}$

The Flipped Learning Network offers the following explanation

Flipped Learning is a pedagogical approach in which direct instruction moves from the group learning space to the individual learning space, and the resulting group space is transformed into a dynamic, interactive learning environment where the educator guides students as they apply concepts and engage creatively in the subject matter. ${ }^{\text {ii }}$

To language professionals, the concept of the flipped classroom should, indeed, not be such a novel concept. For the last two decades we were teaching communicatively, before that at least audio-visually, often with work assigned to be done outside of class, so that class time could be used for conversation and discussion in the target language, not for vocabulary drilling and tiresome grammar explanations. We just did not call it a flipped classroom, but rather CLT, or task-based learning, or the Natural Approach.

This is not to say that the flipped classroom does not have anything to offer to the language teaching profession. Especially with the technological possibilities we have now and the wide-spread use of mobile devices, we can use this method to our advantage. Keep in mind, though, that flipping works best if we prepare materials that are engaging and keep students on task for a long time, thus we need to invest proper care in selecting or designing our resources. 
Waltje

The flipped classroom method and the proliferation of tablets, netbooks and smart-phones that allow our students to access materials anytime, anywhere will, indeed, achieve nothing if we do not spend a considerable amount of time and thinking on providing engaging, sensible, and authentic examples and tasks: We can lead the horse to water, but it still has to drink (and hopefully continuously enjoy the drink!) Only by providing better content, pedagogy, and engagement will we lead our students to better performance. This is where a tool like eduCanon comes in: To achieve the highest effect, the flipped classroom relies heavily on (mobile) technology.

\section{What is Mobile Learning?}

How does "mobile" learning differ from other approaches to teaching and learning? At its best, Mobile Learning encompasses an advancement of learning that strives to do more than merely replicate ordinary teaching and learning methods with updated technology. At UAEU, my home institution, we define Mobile Learning as "an integrated educational and technological ecosystem supported by compact, highly portable, ubiquitous digital devices to enable interactive learning within and beyond the physical instructional environment".

UNESCO, in its Policy Guidelines for Mobile Learning ${ }^{\mathrm{iii}}$, lists the following characteristics and benefits of Mobile Learning:

Mobile Learning can

- Expand the richness and equity of education

- Facilitate personalized learning

- Provide immediate feedback and assessment

- Enable anytime, anywhere learning

- Ensure student-centered learning in the classroom

- Build new communities of learners

- Support situated learning

- Enhance seamless learning

- Bridge formal and informal learning

- Assist learners with disabilities

- Improve communication and administration

- Maximize cost-efficiency 


\section{What Is eduCanon?}

eduCanon is an online learning tool that enables even technologicallychallenged individuals to build and share interactive video lessons. Teachers begin with any YouTube, Vimeo, or TeacherTube video content and transform what is traditionally passive content into an active experience for students. They can time-link activities that students engage with as the video progresses. Content can then be segmented into easily digestible components which helps to increase student engagement. If the teacher chooses to delve deeper into the application, real-time monitoring can inform the planning of subsequent in-class sessions. Of course, you do not have to rely on finding videos that are already "out there". Although you cannot directly integrate your own videos into eduCanon, it is possible to create one's own video repository: upload your clips to a YouTube Channel, and then integrate your videos from there into your eduCanon lessons.

\section{How Might eduCanon Be of Use?}

First of all, eduCanon can be used in a 1:1 student learning environment to provide materials to students who might profit from additional input. Teachers, however, can also use the application in class as a blended tool, or they can assign eduCanon lessons as homework in a flipped setting. Another more advanced use of eduCanon would be to ask students to create their own lessons as part of a higher-Bloom's project.

\section{What browsers and devices are supported?}

eduCanon is a webapp. While it works on all major browsers, the use of Google Chrome or Apple Safari is recommended by its creators. eduCanon works on Macs and PCs, and it has been tried out successfully on iPads. For those of us who are a bit more tech-savvy: lessons can also be embedded into a stand-alone website, a wiki, or a blog.

\section{How Do I Start Using eduCanon?}

There are 3 steps to using eduCanon. 
(1) Build: Add questions to any YouTube, Vimeo, or TeacherTube video.

(2) Assign: After students register, add your class(es) and assign lessons.

(3) Monitor: Watch student progress in real-time, question-by-question.

After signing up for an account at http://www.educanon.com/signup you can start building your own interactive lessons. You will either need to find a video in one of the supported video-repositories, or you can create your own and upload it to the same sites to access it from there. Once you can connect to a clip, you can easily customize it with interactivity suited to engage and focus your students. There are three easy steps to follow

1. Add lesson information.

2. Copy and paste a YouTube, Vimeo, or TeacherTube url.

3. Click 'Build Question' at the desired moment of the video.



You are now at the point where you can enter text for your questions.

Add answer choices and explanations for each choice, then save and continue to build the next question. 


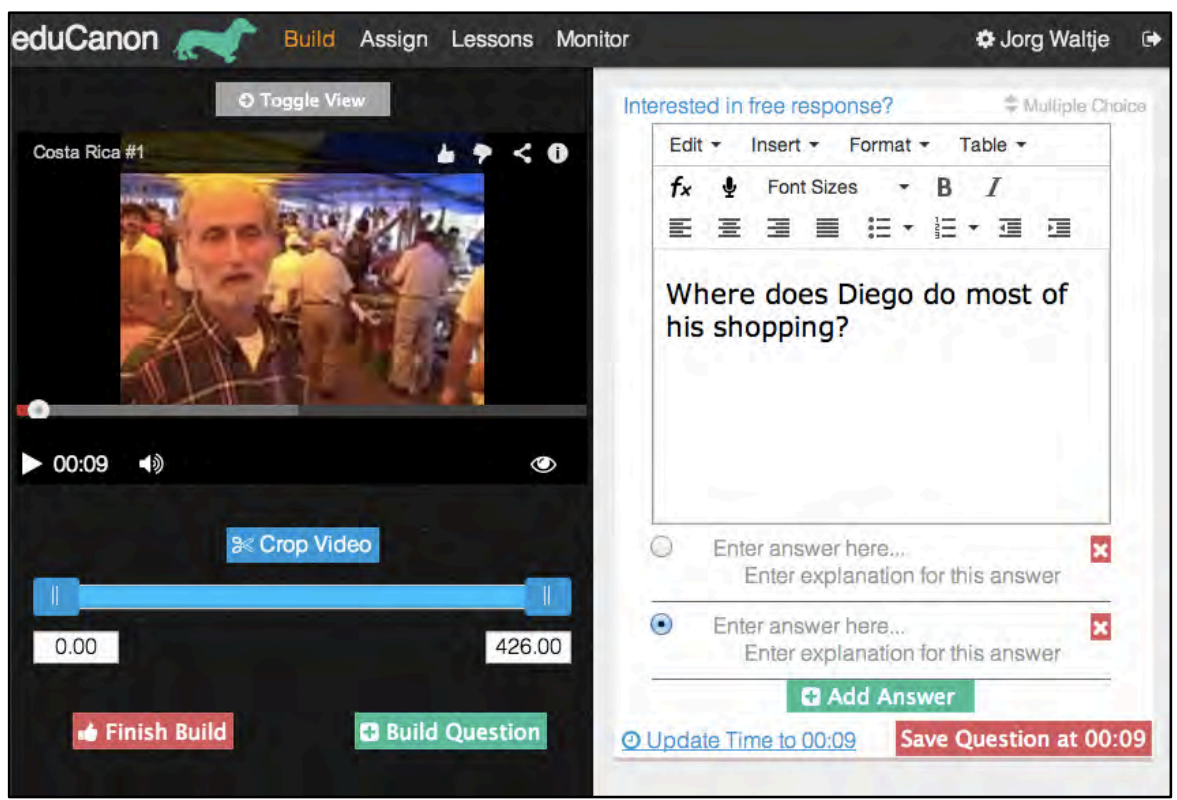

Not all your lessons may be designed for all students alike, some questions might be harder than others, or aiming at different levels of understanding. You can differentiate within your class and assign the lesson that is best for each group of students since it is possible to create up to eight classes in eduCanon. Pick a date to assign a lesson, then drag and drop the lessons you created onto the appropriate class field. You can reorder lessons within any class, the "Week View" Panel lets you monitor assigned lessons for the whole week.

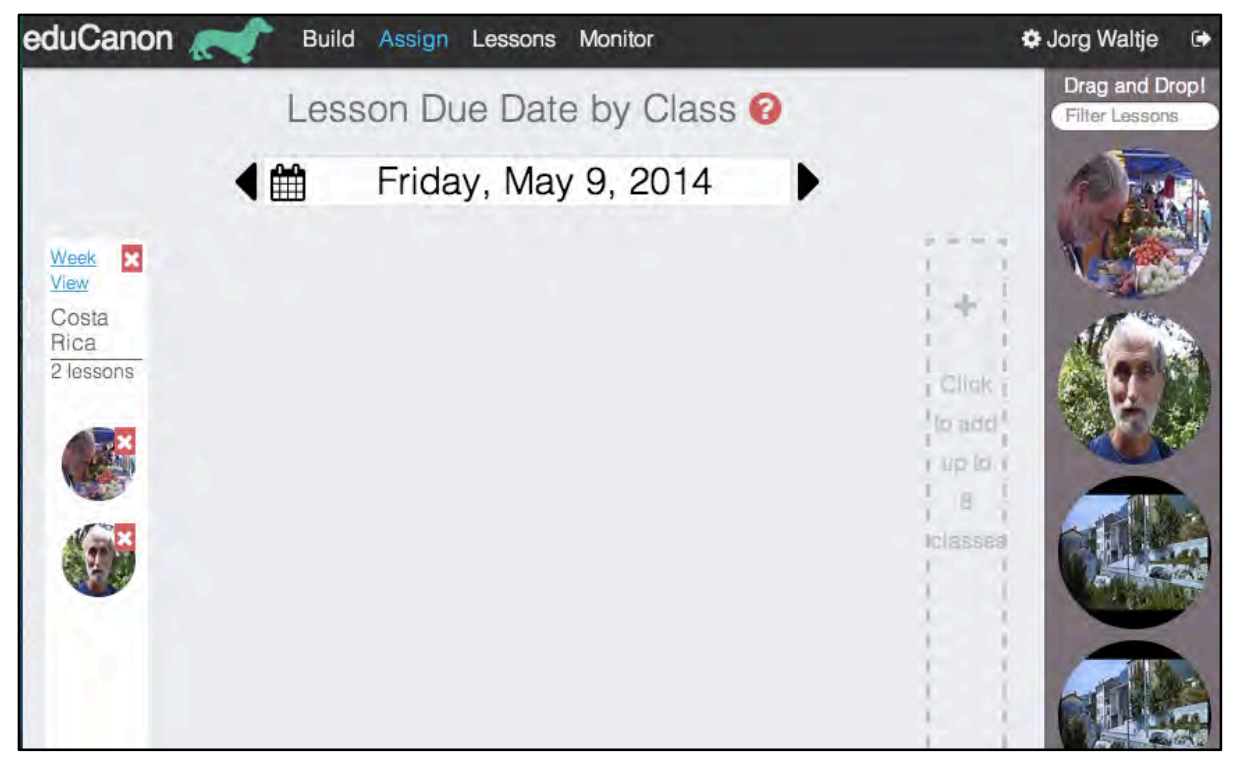


Waltje

Students will have to sign up and create their own accounts. Once they have done that, they can search for your classes by last name, class title, or your personal teacher code that is made available via your Settings Panel. Once the students have added the class, they are ready to interact with your lessons. In the teacher settings page, you can also keep track of your students' usernames and forgotten passwords, reassign students to new classes, edit your own information, and make lessons or classes private.

From the Monitor Menu the instructor can select a class or a particular lesson. In the Dashboard you can sort by question to scrutinize the topics that need re-enforcement and identify who needs extra attention on a given topic. From the info you gain from here you can determine which of your students watched a particular lesson, what concepts you may need to review, and whether it would make sense to group students into different levels.

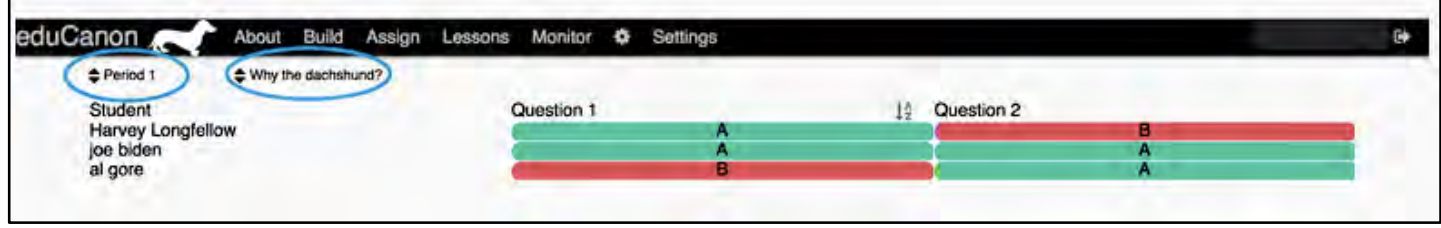

Its ease of use and the inclusion of "learner analytics" truly make eduCanon a tremendous value. It can be adopted in many different learning scenarios and within a wide variety of pedagogical strategies, for example:

- Active learning (A process whereby students use mobile devices to engage in activities, such as reading, writing, discussion, or problem solving that promote analysis, synthesis, and evaluation of class content)

- Problem-based learning (Where mobile devices are used to facilitate learnercentered pedagogy in which learners learn about a subject through the experience of problem solving.)

- Peer Instruction (Cooperative Learning) (An evidence-based, student-centered approach in which mobile devices are used to organize classroom activities into academic and social learning experiences.) 
Language Learning Technology Review

- Project-based learning

(Where learners utilize mobile devices to gain knowledge and skills by working for an extended period of time to investigate and respond to a complex question, problem, or challenge.)

- Behavioral learning (Where feedback and reinforcement can be facilitated by mobile devices)

- Collaborative learning (Where mobile devices are essentially the tool for communication and exchange of resources in interactive groups in which participants actively communicate with one another within a contextual framework which may be facilitated by an online coach). ${ }^{\text {iv }}$

The only drawback at this time is that students can continue to watch a video even if they answered a question incorrectly. It would be nice to program the application in a way that the instructor has the option to "force" the students to review content and supply the right answer in order to be allowed to go forward. Nevertheless, this is a great tool that is highly recommended for its ease of use and its affordability: eduCanon is free, both for teacher and students. A Premium version of eduCanon is available for $\$ 80$ per year. It adds the following features (and supports further development so that the core functionality of the platform remains free for teachers around the globe):

Free Response Type: Adds unlimited free response questions to videos.

Lesson Library Search: Enables users to find and download public lessons to into their own eduCanon library. They can then modify these lessons to best fit their own classes.

Gradebook Export: One-click download of lesson grades in .csv format for easy analysis in Excel or import into current gradebooks. 




Swaroop Raju, co-founder, presenting eduCanon at UAEU

(Thursday, March 6, 2014)

\begin{abstract}
ABOUT EDUCANON
eduCanon was founded by Benjamin Levy while teaching middle school science. The development team now consists of Ben and Swaroop Raju. Their goal is to improve student outcomes in disadvantaged communities and beyond by harnessing the potential of technology. After getting their start in the San Francisco Bay Area, the team has recently relocated to Boston to participate in the LearnLaunchX accelerator.

As the creators point out: "Our belief is that technology should empower teachers. Each student has unique learning needs and teachers don't have the tools to personalize their lessons to those needs." eduCanon in its current format was launched in September of 2013 and since then has grown very rapidly. There is already a database of more than 20,000 lessons that other teachers can pull from and adapt to their own classrooms.
\end{abstract}

\title{
ABOUT THE AUTHOR
}

Jörg Waltje is the Director of the Center for Excellence in Teaching and Learning (CETL) at the United Arab Emirates University (UAEU). Before that he was Associate Professor of Modern Languages and the Director of the 
Language Resource Centers at Ohio University and at the University of Michigan. His current interests include mobile learning, effective faculty development, the use of technology to further intercultural competencies, and tinkering with new technologies for the continuous improvement of the teaching/learning experience in higher education. He can be contacted via email at jorg@waltje.com and he lives on the web at http://www.waltje.com.

\section{ABOUT THE COLUMN}

Language Learning Technology Review is a column that examines new and emerging technologies as they relate to language learning and teaching.

\section{NoTES}

${ }^{i}$ Brame, C., (2013). Flipping the classroom. Vanderbilt University Center for Teaching. Retrieved Tuesday, May 6, 2014 from http://cft.vanderbilt.edu/guidessub-pages/flipping-the-classroom/

ii Flipped Learning Network (FLN). (2014). The Four Pillars of F-L-I-PTM. Retrieved May 6, 2014, from

http://www.flippedlearning.org/cms/lib07/VA01923112/Centricity/Domain/46/F

LIP_handout_FNL_Web.pdf

iii West, M. and Voosloo, S. (2013). Policy Guidelines for Mobile Learning. The United Nations Educational, Scientific and Cultural Organization (UNESCO), France. Retrieved May 6, 2014, from http://unesdoc.unesco.org/images/0021/002196/219641e.pdf?utm_source=Mobil e+Learning+Week+2013_v3_CfP\&utm_campaign $=8885$ b82361 -

UNESCO_Mobile_Learning 3 _28_2013

iv more info on different learning models in Laura Naismith, et. al. (2003). FUTURELAB SERIES (11) Literature Review in Mobile Technologies and Learning, University of Birmingham https://ra.le.ac.uk/bitstream/2381/8132/4/\%5b08\%5dMobile_Review\%5b1\%5d. pdf 